Adaptation in Adaptation in Adaptation in Adaptation

\author{
Wyatt Moss-Wellington
}

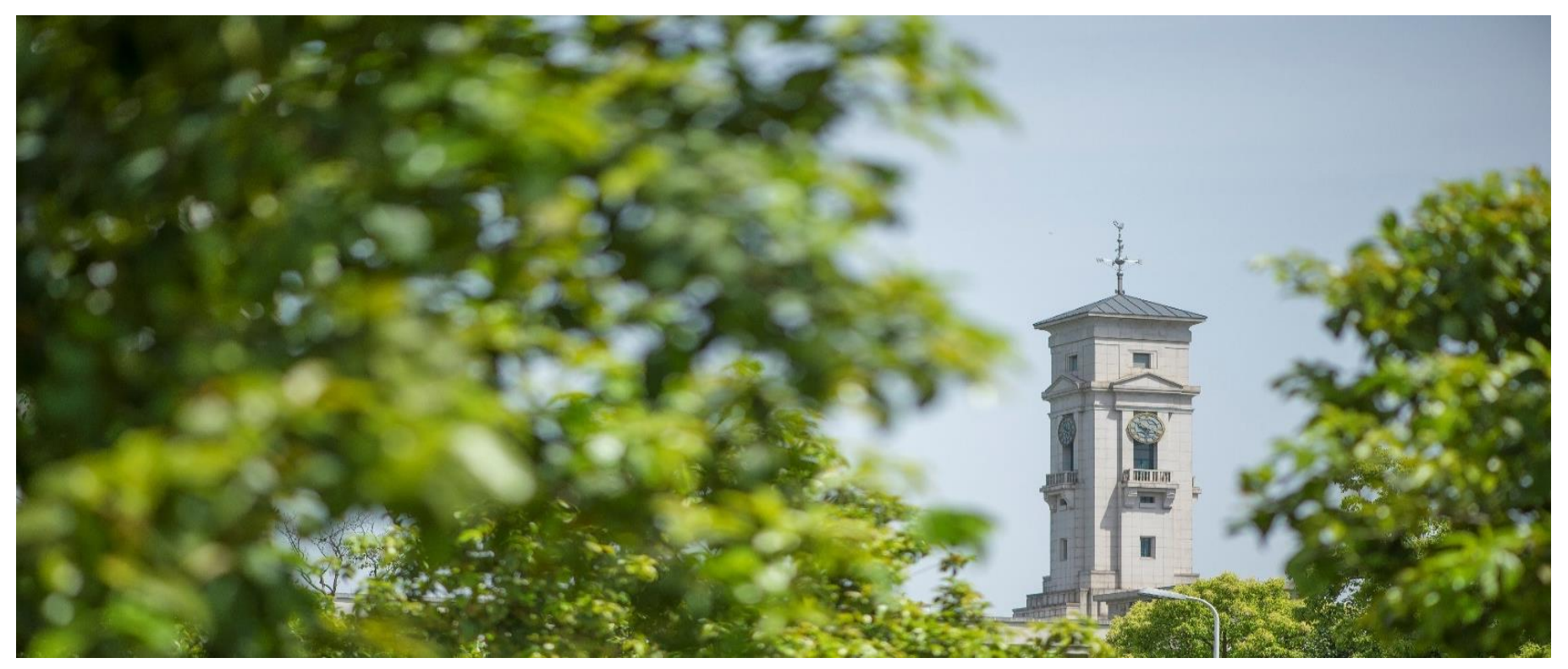


Faculty of Humanities and Social Science, University of Nottingham Ningbo China, 199 Taikang East Road, Ningbo, 315100, Zhejiang, China.

First published 2019

This work is made available under the terms of the Creative Commons Attribution 4.0 International License:

http://creativecommons.org/licenses/by/4.0

The work is licenced to the University of Nottingham Ningbo China under the Global University Publication Licence:

https://www.nottingham.edu.cn/en/library/documents/researchsupport/global-university-publications-licence.pdf 


\title{
Adaptation in Adaptation in Adaptation in Adaptation
}

\author{
Wyatt Moss-Wellington
}

\section{Introduction: What is Literary and Cinematic Darwinism Good For?}

There is a moment early on in Adaptation (Spike Jonze, 2002) in which the fictive Charlie Kaufman (Nicolas Cage) has a truncated epiphany: he envisions his own place within the evolution of life on earth. This would seem to explain many of his own problems; he is subject to selective and fitness pressures, which generate the psychological and cultural conditions he struggles within. When he goes to translate this realization to the page, however, there is no meaningful information to convey. As Joshua Landy puts it, "there is no such thing as the story of everything; a story about everything is a story about nothing."1 The epiphany was short-lived, and seems not so profound after all. I recognize this moment. I have been through it before in my own life, but also my own scholarship. In fact, it is a central challenge in the work of literary and cinematic Darwinism. While it may be true that evolution explains life's manifold iterations, what can it then contribute to our understanding and humanistic documentation of complex human culture and storytelling practices? In effect, our adaptive origins explain everything about life, and yet nothing at all. Jonze and Kaufman use Adaptation to explore our subsequent searches for meaning, and their collaboration yields a filmic model for understanding how and why stories can feel original to us when working from seldom fused influences.

This chapter offers a close analysis of the film Adaptation, and Jonze and Kaufman's treatment of Darwinian themes. It uses Adaptation to prompt questions regarding evolution's use in the humanities, and ultimately asks how we know when 
we are engaged with original thinking, or when we have created something hermeneutically new: how is meaningfully new information made? I demonstrate first the methods through which Adaptation draws equivalence between biological and narrative heredity. ${ }^{2}$ Such a reading, however, throws up new questions; asking what use Darwinian theory is in cultural analysis prompts us to query how we draw meaning from nature, which offers us no prescriptive guidance in itself. I argue that "passion," as it is described in both Adaptation and Susan Orlean's The Orchid Thief, is a process by which we draw meaning from nature - passionate narratives describe in affective terms our responses to natural environments. Hybridizing passions can create new stories. I conclude with a model for understanding the genesis of original ideas and information based on these notions of human and narrative hybridity. Ultimately, Adaptation's passionate originality demonstrates a powerful realization of the philosophies of self-agitation and effortful intersubjectivity that underscore Jonze and Kaufman's work together - and can be read as an analogue for the collaborative labor inherent in filmmaking processes. Rather than blending calcified and familiar genre conventions removed from their relevant contexts, Adaptation amalgamates passionate components of a range of other people's narratives that feel alive because they respond to current environments and their social pressures. For example, the film hybridizes the conflicted sentimentality and sincerity of millennial Hollywood filmmaking, the unbridled philosophy of concurrent Indiewood filmmaking, for which Jonze had so quickly become a figurehead, Orlean's insecurities from The Orchid Thief and Kaufman's insecurities from inauguration in an industry that appears antithetical to his most cherished values.

The problem initiated by Charlie's ${ }^{3}$ epiphanous moment - that our adaptive origins explain both everything about life and nothing at all - is also central to the 
skepticism leveled at literary Darwinist theory. Chief among these objections is that it appears to close off channels of narrative inquiry by making them subject to the more spurious and speculative universalisms of evolutionary psychology; ${ }^{4}$ it finishes the debate by telling us what our lives are, rather than speculating what they could be, or questioning how to live, ethics that are at the core of humanistic narrative concerns. In Adaptation John Laroche (Chris Cooper), for example, motivates Darwinian explanations for all manner of events, and they often conflict with one another. It is no coincidence that when John calls mutation "the answer to everything," the conviction then permits him a pseudoscientific self-superiority, as he continues: "When I was a baby I was probably exposed to something that mutated me, and now I'm incredibly smart." At other times in the narrative, we will see, he moots entirely contradictory views on natural selection.

But this is precisely what Charlie finds out: that conceiving of narrative's ongoing evolution in the context of human selective pressures and adaptive variation is a beginning, not an end per se. It is the entrée to further work. This is where Jonze and Kaufman's creative process begins, as does the hermeneutic work of Darwinian theory. In effect, if one ends with an assertion of survival pressures, we get bad results: narratives of unilineal progress, social Darwinism and eugenics all cease their exploration into human evolution and claim some naturalized version of its ends. These notions are evoked early in the film when John listens to a tape advocating an axiom of Darwinian "progress towards perfection." But we should look instead to the use of evolutionary biology today: the fight against infectious diseases asks open questions regarding our ongoing coevolution with viruses, and the way we might manipulate the environments in which the disease thrives to shape the way it lives with us $;{ }^{5}$ we continue to use evolutionary evidence to enrich rather than finish our 
narrative of human pre-history, how our ancestors moved across the globe and the cultures that developed as a result; ${ }^{6}$ we use the biological evidence of these histories to tear apart the closed narratives of racial essentialism; ${ }^{7}$ and Eva Jablonka and Marion J. Lamb represent a vanguard in detailing the symbiotic relationship between the "soft inheritance" of culture and biological heredity, which we will return to later. ${ }^{8}$ The apprehension of our rich cultural lives as shaped by evolutionary pressures can render our narratological conversations precise as it furnishes us with a more reasonable understanding of human behavior, social psychology and capacities for change. Sociobiology is an open rather than a closed field of inquiry.

\section{The Film Becomes Hybrid}

Adaptation follows Charlie Kaufman's fraught attempts to adapt Orlean's new journalistic novel The Orchid Thief. ${ }^{9}$ It is ostensibly the story of the creation of the film we are watching; it is also Jonze's second and final feature film in collaboration with Kaufman, after Being John Malkovich in 1999. In Adaptation, Charlie struggles to write an original work that simultaneously lives up to his artistic ideals while appeasing his Hollywood commissioners. Meanwhile, Charlie's fictional, laidback twin brother Donald thrives in Hollywood, attracting romantic partners and writing a successful, conventional thriller script called The 3. The narrative is interwoven with an increasingly fantastical version of Orlean's own writing process and her interactions with subject John Laroche, the nominal "orchid thief." Eventually Charlie invites Donald to help him with the Adaptation script, and the film we are watching begins to emulate many of the Hollywood conventions Charlie had initially tried so hard to resist. 
So how do these concerns of hybridity play out in Adaptation, the film? To begin answering that question, let us first skip to the end. Adaptation's closing act has been read as strictly ironic ${ }^{10}$ or self-contradictory ${ }^{11}$ in its endorsement of those conventions Charlie, and perhaps his presumed audience, have stood against: the trappings of Hollywood entertainment. Yet these readings overlook the sincere gestures embedded in the film's latter third. The first thing I want to demonstrate is that this ending is not so simple; it is a blend of narrative modes rather than a sharp transition between art film and emotionally corrupt entertainment. For instance, when Susan (Meryl Streep) cries, "I want to be a baby again, I want to be new," upon the death of her lover, the sentiment rings true and appears to belong to the earlier half of the picture in its referencing of human development (likewise philosophies of intersubjectivity linger in Charlie and Donald's latter conversations). This moment also reaches past Susan's transformation from erudite and unattainable femininity to adulterous murderess, ${ }^{12}$ putting an end to Donald's film's reduction of its female lead to dichotomous male fantasy. Streep's performance, similarly to those of Cooper and Cage, attempts to incite genuine emotion amongst the silliness of car chases and alligators, in which one might glimpse a tension between the screenwriter's sense of emotionality ${ }^{13}$ and the director's, ${ }^{14}$ especially as Jonze's later oeuvre and short filmmaking embraces sentimentality as a narrative device, an issue Kaufman has struggled with. The affective narrative pleasures Charlie had railed against as antithetical to "real life" now appear to be permitted. All of the characters express genuine sadness and self-doubt in the midst of chase sequences, and this affect is blended with the suspense, the horror, and the reflexive humor of these sequences, especially in the on-again-off-again incidental music, incorporating satirical "nature sound" loops reminiscent of musique concrète alongside a more conventionally 
emotional orchestral score. Before they attempt murder Susan and John both hesitate at length, betraying real struggle as if Donald and Charlie's scripts were grappling internally within the characters. We care for Charlie as the first half of the film has so thoroughly documented his rejections and failures, and the film has speculatively constructed the inner lives of Laroche (depicting a traumatic car accident) and Orlean (depicting an imagined alienation from her social scene). Perhaps most of all, Donald and Charlie's final conversation centers upon love and care and heart, Hollywood's obsessive values that might not work so well when stated simply on their own, but grafted onto a richer narrative can gather eudaimonic meaning, or a sense of narrative fulfillment and truth-seeking purpose that are not bound simply to hedonic spectatorial and emotional gratification. ${ }^{15}$

The point is that our reception of these events is mediated by and charged with the philosophical film that we have just sat through. The popcorn conventions are now loaded with the weight of that memory. Adaptation's various stories are not in opposition but are complimentary because our memory renders them comparative; the film has become hybrid. The philosophy is enriched by the emotionality of its conclusion, and the audience works to read the conventions of the closing act within the context of the film's setup, each prompting reflection on the other. Equally, the seeds of this ending were in the film from the beginning: Susan's romantic attachment to her subject begins at his first Darwinian aside. ${ }^{16}$ The first time we see John on screen, he is being tailed both by an ominous score that suggests the opening of a thriller movie, and a policeman casting criminal doubt on his collection of rare plants. This imagined scene prefaces the originary court trial of The Orchid Thief, yet we also see evidence of drug-induced behavior in John and his colleagues long before Charlie invites Donald onto the script and "turns" to his more histrionic narrative vision. 
Within this structural reciprocity, and the metaphor of Kaufman as twins, we might ascertain that we start our lives as hybrid, but can choose to accept and explore this hybridity or disavow it. This would mean, too, that in the spirit of Kaufman's selfcritique, we cannot strictly separate Donald and Charlie to damn just the one. The purpose of the end is not to make clear the failings of a particular narrative type embodied by Donald. They are co-dependent, part of the same machinery and indeed the same Hollywood, the same Academy that embraced the present film, so any attempts to simply abhor a narrative type and its conventions are undermined. In a way, in consistently returning to Kaufman's failure to produce art from principles that reject other arts, Adaptation upbraids the hypothetical viewer's very own elitism that would like to make it easy to separate corrupt narrative pleasures from the rest. ${ }^{17}$ As Kaufman himself put it simply, "What I wanted to end up with was a discussion rather than a conclusion." 18

We might note, too, that by its conclusion the film has never quite embraced those Hollywood conventions as a replacement or direct contrast, but instead twists them into something new and more moderated, something hybrid: Charlie does not quite get the girl; he does not drive off into the sunset but rather grey LA; Charlie's voiceover returns, yet still retains a hint of the narcissism and fretting that opened the film as he considers having Gérard Depardieu play his role; the flowers are not orchids in an exotic setting, but the more humdrum daisies that go about their everyday nodding to the sun on a median strip; the floral time-lapse returns us to comparative philosophical work in the very juxtaposition of plant and human temporality $;{ }^{19}$ and we should remember that the song that plays over the credits, "Happy Together," is not only arch in its eccentric performance ${ }^{20}$ or its thematic relation to the film text, it also features Flo \& Eddie of The Turtles, who went on to 
work with Frank Zappa - they represent a hybrid of pop and avant-garde. Many iterations of the song culminate in that iconic and twisted version of the vocal round as fragments of the tune are layered together, a melody that doubles back on itself to create harmonic newness, a hybrid created from a singular melodic source or a "happy togetherness" of asexual reproduction. The theme of asexual reproduction is also borne out in the overlapping dialogue of Cage's humorous performance as twin brothers, the tongue-in-cheek phenomenology of the final bromide (emphasizing the "bro" in "bromide") that "you are what you love, not what loves you," and the film's copious onanistic metaphors $;{ }^{21}$ not just masturbation, but all manner of interruptions to the sexually reproductive. ${ }^{22}$ As Lucas Hilderbrand points out, "Even the lyrics of 'Happy Together' are not actually about being together but about fantasizing' and as it has appeared previously as a love song between brothers "it functions as an ode to oneself since Donald functions as Charlie's imagined alter-ego." 23 The film also establishes interest in the cross-pollination of melody into harmony during a scene in which Susan asks John to recreate the sound of a dial tone by humming with her (which also occurs after Donald's intervention but appears to belong to Charlie's half of the film). In any case, "Happy Together" appears as a conventional pop song but speaks back to the film's philosophy and its facetiousness not only poetically, but in its musicality as well.

On one hand the message here should be clear: hybridity is a lived experience. It is unavoidably the stuff of life; it is what happens to us rather than merely a philosophy to consider. But if this is the case, what benefits might exist in being aware of the Darwinian adaptation within story adaptation? Can we gain a fruitful and relieving acceptance of our own selfhood as hybrid, can we enrich our relations with 
others using the new philosophy that develops, and can we have some autonomy or interactivity and shape its impact on our lives?

In splitting himself into two characters, Kaufman suggests that both of these narrative interests exist within us, so it is a matter of how much we allow these creative imaginings to coexist rather than erect strictures that prevent us from drawing on a wider range of external narrative sources. Popular screenwriting guru Robert McKee is somewhat lambasted for these strictures (both the "Ten Commandments" drawn from Story and his antagonistic oratory upend any claim to "guiding principles" rather than strict rules), which prevent story cross-pollination (like being bound to concretized genres or archetypal narratives) and essentially inhibit the ability of narrative to mimic the eternal adaptive cross-pollination of life, and thus, hopefully, feel alive. ${ }^{24}$ In turn, however, the fictive Robert (Brian Cox) is permitted to lambaste Charlie for his own dogma regarding a "real world." In his cynical and selfregarding conviction that in reality "nothing much happens" and "people don't change," Charlie reveals condescension toward the lives and quotidian dramas of others in the world. He then realizes how the narratives he tells in screenwriting are intimately related to the narratives by which he lives his life. By the end, we see that Kaufman and Jonze have used every other narrative at their disposal to craft something new: Robert's diatribe against voiceover causes Cage's narration to disappear from the film as we are watching it, provoking us to reflect on what Charlie's autobiographical musings brought to the narrative as a whole ${ }^{25}$ Donald's notion of "split personalities" using "trick photography" winds up in the narrative as Kaufman twins rendered in "split screen photography"; everything from studio executive Valerie's (Tilda Swinton) gentle prodding to agent Marty Bowen's (Ron Livingston) horrific sexism have an impact on the kind of romances that the 
screenplay ends up scrutinizing. So likewise, if we maintain strictures against the emotionality and plot devices associated with Hollywood storytelling, we might miss their use in a variety of other contexts. Adaptation does achieve originality in a creative "loading" of narrative elements.

Perhaps, then - just perhaps - the more hybridized a narrative, and the more it draws from a range of sources, the more interesting it becomes, simply because there is more metacognitive work for the viewer to do. This, I believe, is the demonstrative argument of Adaptation. The more psychological argument regards our existential acceptance of hybridity. Before moving on to answer some of my broader questions of Darwinian narrative theory, first I turn to look at the film's treatment of those thoughts that get in the way of such an acceptance, chief among them fantasies of originality and sole authorship in the creative process.

\section{We Are Hybrid in Narrative as in Biology}

The film's first few images, a facetiously cinéma vérité reconstruction of the Being John Malkovich shoot, pillory assumptions of authorial dominance, its inevitability or desirability, ${ }^{26}$ by providing some manner of hostile directorial role to the film's nominal celebrity. This prologue also carefully excises the figure of Jonze from the film - he is not present in the story of either film's creation, a knowing wink that gently undermines auteurist readings. In its affecting of documentary-style footage, Adaptation announces that it is taking on a fantasy of and a presupposed "idea" about realness, or more specifically, that particular comfort we derive from

presuming that we can witness signifiers of authentically captured reality. ${ }^{27}$ The scene may seemingly introduce a gag regarding the industry's disinterest in a key creator in 
the filmmaking process - the writer - yet it also suggests the way we use our more idealistic visions of creative processes to disavow hybridity's place in our lives. If narrative is where we go to fantasize, a key fantasy that we tend to engage with is that of life as more authentic when we do not have to hybridize our thoughts, our lives, our very being with others. The scene evokes debates around auteurism and documentary realism, and gently undermines them, to introduce its key theme: our metacognitive thinking about hybridity.

At the beginning, Charlie is also beholden to this idea when he claims to Valerie that he wants to avoid an "artificially plot-driven" narrative and challenges himself to write a film "simply about flowers." 28 Of course, all of the plot points he mentions in this early scene as examples of inauthentic narratives will end up occurring in his own script, and will twist the narrative of Adaptation in surprising ways. In fabricating a binaristic ideal of two narrative modes and putting them in opposition, though, he has set himself up to fail, as the history of narrative is the history of hybridizing inherited stories - there can be no binary oppositions here. He imagines a lack of outside influence as true originality, but again there is no definitive originality, only constantly amorphous thoughts following from thoughts. When we follow the lineage of the present story, we see that Kaufman has adapted Orlean's book into something new, just as Orlean has employed the new journalistic method to craft a narrative - the originating New Yorker article and then The Orchid Thieffrom John Laroche's life, which she draws from and balances against the heroic narratives John distributes of himself and connects to other narrativized lives including key figures in the tradition of orchid hunting,${ }^{29}$ and finally when we see a later version of John espousing self-realization platitudes and get-rich schemes, we recall that John's life will similarly be informed by cultural narratives we will never 
bare direct witness to, but have been adapted somehow into his own experience. Yet Charlie is not just drawing from The Orchid Thief, he is cross-referencing against Darwin's own writings, ${ }^{30}$ he is drawing inspiration from his experiences on past work like Being John Malkovich, he is working in his autobiographical narrative as did Orlean before him, and Darwin before her, he is influenced by the interjections of tandem authorities like Valerie or Robert, and of course he is including some ideas for an action-thriller script that exists elsewhere in Kaufman's imagination, as a more reckless and intrusive twin of the philosophic self he more closely identifies with, for a large part of the narrative acting as a doppelganger who psychologically hounds him. ${ }^{31}$ "We share the same DNA," Charlie laments of Donald when he says something stupid, the irony being that they are both Kaufman, both characters representing components in his imagination: we are hybrid beings in narrative just as in biology.

\section{Drawing Meaning from Nature}

In this very real sense, a literary Darwinism appears germane. Yet the discipline is not simply concerned with using evolution as a metaphor or concept to play with, it is concerned too with historical work (explaining the emergence of stories and genres within environments with varied challenges to our continuity), and hermeneutic work (reading narratives within the context of how they speak to our motivating selective pressures). Different stories emerge in different environments. For example, "Donald's ability to adapt to the Hollywood environment allows him to succeed quickly," 32 and his willingness to fit in shapes the kinds of stories he tells. Jason Mittell writes: 
We can see Charlie's character arc as evolutionary, as he learns to adapt to the hostile habitat of commercial Hollywood and survive by writing a script suitable to be filmed; additionally, he proves to be more adaptable and resilient than his twin brother, surviving while Donald dies, and thus he is able to 'reproduce' through the creative means of filmmaking. ${ }^{33}$

On the other hand, Charlie's opening thoughts immediately connect philosophicalnarrativized goals to the evolutionary fitness pressures that drive them, and then to the existential questions that open up in reflection of these connections: "Do I have an original thought in my head? ... My bald head. Maybe if I were happier, my hair wouldn't be falling out. Life is short." As Peter Marks puts it, "Intimately aware of his own mortality, operating in a filmmaking environment threatened by novelty, and with a crippling sense of his lack of originality, Kaufman in his own mind faces forms of personal and creative extinction." ${ }^{, 34}$ And then, I might add, he deals with this existentiality through narrative, and this is what we witness throughout the remainder of the picture. But it is not just narrative as a coping mechanism that the Darwinist might study, nor the way our fictions talk to themes related to our survival (in Charlie's case a social survival connects very directly to his sexual survival), we want to know too how acts of narrative communication and fictive imagination of themselves might serve our evolutionary continuity: storytelling's function.

These scholarly goals of course run the very real risk of intentional and natural fallacies, of romanticizing nature, and of using evolutionary assumption to close debate. The problem is that we are often romantically motivated, and we might need to reduce multi-faceted knowledge to a manageable prescription, or in Susan's words 
to "whittle it down" to a passion in order to derive meaning from complex information. Adaptation explores some of these tensions, too. At a nature show, John, who has previously been petty and insularly concerned, surprises Susan (and hopefully the spectator) with a soliloquy that does articulate with clarity the wonders of coevolution: the mimicry of the orchid, attracting the "lovemaking" of insects that pollinate them, and how an entire planet of life depends upon their mutualism in a way they will never be cognizant of; at the same time, he infuses his monologue with a romantic sensibility when he anthropomorphizes natural processes into an expression of "love," insinuating natural design and deific order in his claim that "by simply doing what they were designed to do ... they show us how to live" [emphasis added] and concluding with a personally prescriptive appeal: "now when you spot your flower, you can't let anything get in your way." The soundtrack sways with him, as the strings rise and the vocal sound "changes dramatically (clearly this part was recorded in a studio, without the ambient noise of the set)." ${ }^{35}$ John's chief example is a more palatable cooperative coevolution rather than, say, a parasitic coevolution, which also comprises co-dependent life on earth. John turns his realization of natural sciences into prescriptive meaning making; his musings even include that famous line at the foundation of human ethics, "how to live." This moment causes us to wonder how we might do the same, translating our comprehension of natural phenomena into codes for living. ${ }^{36}$

John will later wax lyrical about the mutability of orchids as an indication of their ability to "figure out how to thrive in the world" (again attributing human intent to nature when he personifies the plant), but Susan has had time to think and talk back now. The difference in human adaptation has something to do with our memory, she suggests. Susan gives voice to Charlie's concerns of narrative adaptation in a broader 
Darwinian context when she retorts that adapting is "almost shameful, like running away." The remark speaks again to that other adaptation of the film's title: Kaufman's (and perhaps narrative absentee Jonze's) struggle to adapt to the Hollywood community, and the values of cultural evolution that, for him, are at stake; and again, a human ethic is drawn from nature, which is something we all must do in order to live even while nature offers us no such guidance.

Questions of responsibility run deep in this film, but what I want to focus on now is Susan's other realization when attempting to draw moral meaning from natural mutation: "yeah but it's easier for plants," she says, "I mean, they have no memory." Due to our extraordinary capacity for memory, human motivations are complex; they are contradicted by competing information and competing ethics, as well as codependencies with other life that must be balanced against self-interested survival needs. Memory creates dissonance and conflicting incentives that are elaborated into complex culture, just as our memory of the first two thirds of the film create narrative dissonance by its close. But this is just the beginning. We also have communication occurring across millennia through the narratives of recorded history. Jablonka and Lamb call this "symbolic inheritance" which feeds back into the environments in which our genes are expressed, introducing latent, translatable and mutable information from our past. ${ }^{37}$ Their point is that such a cultural inheritance is inseparable from genetic, epigenetic and behavioral inheritance (they call these the "four dimensions" of evolution). These different hereditary variables interact to shape who we are. Evolutionary biology has some powers to explain both individual and cultural variation, but in the humanities we can still ask: given this information, how ought we live? 


\section{The Other Side: A Horror of No Reflection}

A brief digression would be worthwhile here to explain the sources of the film's horror, opening as it does one of Adaptation's central ethical and affective hybridities - that of the horror comedy. From the first sequence depicting a four billion year history of Los Angeles, a dissonant score and murky imagery both figure prehistory as dark, mysterious and terrifying. This mystery is carried through such imagery as DP Lance Acord's naturalist night lensing, especially in car interiors during which he exaggerates the reflections in the actors' glasses and eyes, making them appear somewhat alien. These flourishes clearly bring out the mortal dread of reflection on our place in the universe, but even more so, the film includes gender, class and indigenous politics as sites of horror. The film's horror suggests an "ought" question by articulating its antithesis: it depicts various unethical acts, how not to live. Kaufman may have adopted some Hollywood conventions at the end of his script but he still points to many of its abject cultural conditions, suggesting aspects of Hollywood's culture that he would not like to sustain. The clearest example is an absurd male hyper-sexuality and objectification that intrudes unpleasantly upon the film, especially in the character of Charlie's agent Marty, the brisk appearance of whom triggers perhaps the clearest embodiment of the film's "meta-machismo,"38 or the burying of unremarked-upon sexism in its meta-narrative. However the horror here arises from Marty's complete lack of self-reflexivity around his sexism; it is precisely the point that objectification is so compulsive as to be intrinsic to the environment he exists within. His lines about anal sex sound like they are derived from one of Hollywood's male fantasy sex comedies - a Seth Rogen film, perhaps but they are out of place in a movie that calls for reflection, they fall flat, and drained 
of humor these lines reveal the horror undergirding callous dialogue that we are so often encouraged to receive as playfulness.

Thus Adaptation's gender concerns, class politics - especially as expressed within Susan's literary community ${ }^{39}$ - and the seldom remarked upon indigenous politics all represent places of horror in the script for their lack of reflection. They serve as a reminder that Charlie does indeed have real and reasonable gripes with the communities he has to work within. But complex thinking without clarity also has its own horror attached. As Sergio Ruzzo points out, the disinterest expressed by the Seminoles of Adaptation is a far cry from Orlean's account of complex interactions between white and indigenous communities in The Orchid Thief (including the politics circulating the Fakahatchee, the detail of Laroche's nursery plans and his patchwork alliance with the Seminoles). ${ }^{40}$ In essence, the Seminoles belong to Donald's plot, but their inclusion works because it permits them to express disdain back towards colonizing legal institutions from the outset. John and his indigenous colleagues initially attempt to talk their way out of trouble with the law using a sarcastic relativism, making a joke of legal dissonances that native peoples must navigate: they are supposed to perform their authentic indigeneity in order to make rights-based legal claims, but here they roll their eyes and refuse to take them seriously. The production of this disdain - the only reasonable response to complete removal of their cultural autonomy - is another kind of horror. Their response has the potential to call into question notions of static nativism that have plagued indigenous activists the world over, in that indigenous peoples must perform a singularly authentic - and thus unchanging - version of their culture in order to argue for their legal status in systems that cannot reconcile their right to ongoing cultural evolution with their claim to a historic relationship with the land; ${ }^{41}$ in Adaptation, even those 
legal arguments are in service of John's whims rather than their own autonomous needs. Indeed, the Seminoles are seen studying their fingernails during the court trial, almost completely removed from proceedings. The unmitigated aloofness of the Seminoles in the Adaptation script, relieved only by a fictional drug, crafts horror from an utterly sad and utterly reasonable detachment, exaggerated into a stereotype of mutual disdain.

Ultimately the indigenous politics of the book (that we only catch glimpses of in the film) supports Jonze and Kaufman's thesis by pointing to its converse: if we do not allow one another's narratives of self-identity to be alive to mutation and change, our relations calcify into exploitation. Unlike the non-fictive book however, the Seminoles, and likewise Charlie's agent and Susan's social scene, are completely imaginary, but this same problem in each case is hyperbolized to a horrific extreme. Stereotyping figures while pointing to their unreality - from Charles Darwin (Bob Yerkes spluttering over a manuscript in a desaturated hovel) to the Seminoles, to Kaufman's own agent - is one way the film produces horror. Similarly, when Charlie and Donald take on some bastardized version of Susan's former investigative role, she takes on their more depraved earlier roles. All of this horror occurs before we even catch a glimpse of the comic deus ex machina alligator, at which the cerebral and visceral possibilities of the horror comedy collide.

\section{Passion Connects Information to Mortally Felt Consequences}

So one of the paramount horrors in Adaptation - from Marty's offhand anal sex references and the reasonable detachment and disdain of the Seminoles to the uncaring classism of the New York literati - is a lack of reflective passion. This 
vivifies the other world Kaufman has envisioned to fight against. He wants his own screenplay to represent the very opposite of its dispassionate and unambitious passivity, and that, for him, would be a creativity in imaginative resistance, and an originality of thought in its refusal to adapt to the worst clichés surrounding the screenwriter in Los Angeles. So now, let us at last follow his journey through until we arrive at the genesis of original thought.

To begin, Adaptation wears its narratological deconstructions on its sleeve, making it appear that self-referentiality is its originality, when in fact its particular metafictive address - the self-creating narrative - has innumerable precedents on screen and on the page. ${ }^{42}$ If all of our new narratives are amalgams of pre-existing narratives, Adaptation explicitly asks, how do we avoid Ouroboros in our creative thoughts? A favorite theme of both Jonze and Kaufman - being trapped inside one's own mind, or the existential sadness of our intersubjective limitations - here becomes an admission that even when we attempt fidelity to somebody else's story, we are telling our own. The Ouroboros Charlie mocks in Donald's script becomes the central conceit of his own: we rehash old stories to make something new, and this will always feel unoriginal and be subject to self-doubt.

It would be all too easy to say that the source of originality is hybridity. Much like the film's central failed epiphany, it encapsulates everything and so explains nothing. What is it, then, that must be "whittled down," and if passion is inherently reductive, what kind of profound originality are we then capable of? Passion connects with our search for meaning, and when we face up to passion's ephemerality (Laroche's abandonment of every passionate cause), it is to admit to the very limits of personal meaning making (one of Orlean's "sweet, sad insights"). But passion is not foremost about acquisition or obsession, like finding and owning rare flora and fauna 
- using these tools it is always doomed. Passion instead connects us to others. Passion motivates a search for connection without which Charlie has no need to tell a story, no drive to even be original in the first place. That is why he must begin with something he cares about. Passion is what "whittles the world down to a more manageable size." It is Charlie's turnaround moment: he can begin reductively and then work outward to include other narratives.

In Adaptation, passion produces the germination of originality, but not its realization. Where Orlean has a passionate interest in detailing the lives of others, Kaufman realizes he is mostly passionate about himself, and begins his narrative from there. He has now "whittled it down" to find a beginning, but to end there would make Adaptation boring like Kaufman's latter films, his almost completely selfabsorbed directorial work. He then merges his own passions with those of others, including Orlean, Laroche, and even those much-maligned Hollywood executives, to craft something new. The Orchid Thief was interested in what Ted Conover calls the "monomania of collectors. $"{ }^{43}$ But, he observes, creativity regularly works outward from monomania into its complication, putting it in tension with other passions until they unite. In the narrative arts, we require more than the connecting of various stories to hybrid forms, we require the connected passions of various narratives to make hybrid passion, somewhat like the proliferated cerebral and emotional passions at the end of Adaptation. This is the difference between what I have been distinguishing as "new information" and "meaningfully new information." For what is passion but the way these stories connect to our deepest hopes and fears, driven by our most mortally felt consequences - adaptive pressures refracted through the myriad symbology of cultures steeped in narratively recorded histories? Stories describe, often in affective 
terms, what it is like to live the experiences that evolutionary biology explains, making them meaningful to us.

The Orchid Thief, too, reflects on its method of immersion and learning so that an object of interest becomes "part of your life." 44 Yet in new journalism and its correlate scholarly practice ethnography, it is after the fieldwork and participant observation that one returns to the various narratives of their own everyday and compares them back to another culture's sense of being that produces a new, informative outlook. ${ }^{45}$ One could mix one's own particular passions together into something new, but an interest in the passions, the lifeworld, and the knowledge of another might formulate a new and more surprising union of ideas - originality. Humanistically enough, this could include those whose passions we struggle the hardest to see the value in, like those of Hollywood's more formulaic storytellers. Together, they mutate into a kind of humility, which might seem surprising given Kaufman's insistence upon his own narcissism. This is humility not just in that Cage wears a fat suit with a mock-balding pate, but in Kaufman's portrayal of himself as stumbling upon rather than generating an original narrative, in concert with others. It was his very ambition to convey the evolutionary genesis of passionate thoughts and feelings that led him to this collaboration, and provides one more lesson in Adaptation: that to be ambitious is not to be resolute.

For this, is it not, is the great fear of cultural analysts who shy from the turmoil of contemporary Darwinian debates, that in our ambitious questions of the very nature of life itself we might concoct another eugenics. Marks motivates Stephen Jay Gould's warning against the ills of unilineal progress in evolutionary thinking to make the claim that we should "limit our application of Darwin to the film, or to culture in general, for in an essential way, his ideas are irrelevant to the cultural 
world. ${ }^{46}$ But this exceptionalist notion of human culture ignores that natural selection has produced the environments in which current cultures flourish, and so surely can tell us something about how those cultures operate (if not ever why they operate). Cultural theorists on the whole reject Darwinian analysis because it appears to finish the debates they have tried so hard to open; this is only because they are looking in the wrong place. Darwinian philosophy as holistic explanation might be closed, as in the pitfalls of the most deterministic evolutionary psychology, but evolutionary biology, like all sciences, produces answers only to find more questions behind them, and those questions allow us to become more specific. We map the human genome, but then behind that is the complexifying epigenome. Epigenetics in turn begins to explain how genes modify their expression given the environments they respond to this is crucial, as it renders nature/nurture debates unspecific enough to be redundant. It is, in fact, evolutionary research that has propelled us past such dichotomous thinking.

At worst, this is extended into a call for static arts rather than narrative arts as somehow more real and more nourishing, the suggestion that we fetishize change to our detriment, which appears to me to confirm Charlie's initial unworkable binary of authenticity versus artifice: "a victory for the nonnarrative (the static, the cyclical) over the narrative." 47 Landy rejoices that the film "leaves us, in the end, with the powerful, unchanging beauty of flowers and the strange, unchanging beauty of Charlie Kaufman's soul. ${ }^{, 48}$ It is in fact Darwinism that is open to change, and the determination to locate and describe immortal beauty and objective intellect expressed in the highest terms as "soul" - that is not. Roger Ebert wrote of Adaptation, "To watch the film is to be actively involved in the challenge of its creation." ${ }^{49}$ If that is what we want in theory, to be actively involved in the challenge 
of our own creation, it makes little sense to omit what we know of the biological dynamisms that birthed us. There is dishonesty afoot when we do not accept the place of our life in an adaptive continuum with selective pressures that produce fears and anxieties and behaviors that attempt to prolong the self in various ways (like recorded narratives), the complex iterations of which in turn produce complex culture, and that dishonesty can seize attempts to generate meaningfully new information. This is true of any kind of storytelling, the narratives of film or film scholarship, fiction or causal analysis. When, in scholarship, we make polemical claims, analyze story meanings, politicize hypothetical lives, or work towards prescriptive ethics, if we do not acknowledge sociobiology we miss that part of the story which talks to our genuine capabilities, to our deepest driving motivations, not just how we respond to our environment, but a "gene-culture coevolution," 50 in which we might locate our agency for change.

\section{The Genesis of Originality}

Let us finally return to Charlie's abbreviated epiphanous moment: the point is not just to understand evolution as meaningful in a totalizing sense, as explaining at once all there is to meaningfully know about life. Poor evolutionary theory - in some cases harmful, as in social Darwinism and eugenics - and poor analytical work will end there. In reprieve from evolution as conclusive epiphany, we might address those lines represented as the closing thoughts of The Orchid Thief, that express one kind of "essence" Kaufman and Jonze have drawn from the book and have chosen as the object of their adaptive work. They serve as a reminder that we can accept evolution, mutation and hybridity, explore these natural processes, but never master or totalize 
their ineffable power: "Life seemed to be filled with things that were just like the ghost orchid - wonderful to imagine and easy to fall in love with but a little fantastic, fleeting and out of reach." ${ }^{51}$

With respect to these limitations, what can literary and cinematic Darwinism do? Kaufman and Jonze's argument is first for accepting the hybridity of narrative, and thereafter embracing and creatively exploring it, which, in their case, does indeed produce something unfamiliar and original. My argument is the same for intellectual work, and what I ask is that the descriptive narratives of science and the prescriptive narratives of humanistic scholarship continue to be merged, as they both evolve, into something open, explorative and new. I am not just drawing the parallel between narrative and biological adaptation: that selective hybridization produces variation to create original stories, as it equally produces experimentally new life. Adaptation has already done that. I am using the film to make a passionate and value-laden appeal: that we remain alive to how other people's narratives are alive. I ask that we keep ourselves epistemologically open not just to the knowledge and narratives of others, but the way the knowledge and narratives of others change, and this includes evolutionary analysis as an open field of debate that is constantly updating, not as an end that explains everything. This is the source of human originality; it is how meaningfully new information is made.

\footnotetext{
${ }^{1}$ Joshua Landy, "Still Life in a Narrative Age: Charlie Kaufman's Adaptation," Critical Inquiry 37, no. 3 (Spring 2011): 501.
} 
${ }^{2}$ C.f. Martin Price, Forms of Life: Character and Moral Imagination in the Novel (New Haven: Yale UP, 1983); if narratives provide our best ambassadors for our sense of being, then it makes sense to think of our stories as a kind of life.

${ }^{3}$ I use first names for characters and last names to suggest their non-fictive counterparts.

${ }^{4}$ See Malcolm Turvey, "Evolutionary Film Theory," in Cognitive Media Theory, ed. Ted Nannicelli and Paul Taberham (London: Routledge, 2014), 46-61.

${ }^{5}$ Sharon Moalem and Peter Satonick, Survival of the Sickest: The Surprising Connections Between Disease and Longevity (New York: William Morrow, 2007). ${ }^{6}$ E. J. Michael Witzel, The Origins of the World's Mythologies (New York: Oxford UP, 2012).

${ }^{7}$ See the American Anthropological Association's "Race and Human Variation" webpage, based on the work of Jeffrey Long, Understanding Race, 2016, http://www.understandingrace.org/humvar/race_humvar.html ${ }^{8}$ Eva Jablonka and Marion J. Lamb, Evolution in Four Dimensions: Genetic, Epigenetic, Behavioral, and Symbolic Variation in the History of Life (Cambridge: MIT Press, 2005). We should remain aware that this Lamarckian view of "phenotypic tailoring," too, is an open field of debate, apropos Thomas E. Dickins and Qazi Rahman, "The extended evolutionary synthesis and the role of soft inheritance in evolution.” Proceedings: Biological Sciences 279, no. 1740 (2012): 2916.

${ }^{9}$ Also known as "creative non-fiction," new journalism tells semi-fictionalised accounts of social phenomena usually by narrativizing the reporter's immersion in their object of study. See in particular Tom Wolfe and E. W. Johnson, The New Journalism (New York: Harper \& Row, 1973). 
${ }^{10}$ Peter Marks, “Adaptation from Charles Darwin to Charlie Kaufman," Sydney Studies in English 34 (2008): 19; Julie Levinson, “Adaptation, Metafiction, SelfCreation," Genre: Forms of Discourse and Culture 40, no. 1-2 (2007): 175.

${ }^{11}$ Lucas Hilderbrand, “Reviews: ‘Adaptation'," Film Quarterly 58, no. 1 (2004): 42.

${ }^{12}$ Sergio Ruzzo, "(In)fidelity criticism and the sexual politics of adaptation," Literature/Film Quarterly 36, no. 4 (2008): 311.

${ }^{13}$ Charlie Kaufman, "Why Charlie Kaufman Doesn't Watch Movies Anymore," interview by Michael Koresky and Matthew Plouffe, Reverse Shot, March 23, 2004, http://reverseshot.org/interviews/entry/332/charlie-kaufman

${ }^{14}$ Spike Jonze and Charlie Kaufman, "Spike Jonze and Charlie Kaufman Discuss Adaptation," interview by Spence D., IGN, December 5, 2002, http://au.ign.com/articles/2002/12/05/spike-jonze-and-charlie-kaufman-discussadaptation

${ }^{15}$ C.f. Mary Beth Oliver and Arthur A. Raney, "Entertainment as Pleasurable and Meaningful: Identifying Hedonic and Eudaimonic Motivations for Entertainment Consumption," Journal of Communication 61, no. 5 (2011): 984-1004.

${ }^{16}$ Marks, “Adaptation,” 38.

${ }^{17}$ It also renders absurd the normative critical position of keeping hawkish lookout for reliable and fixed indicators of a film's artistic credibility or signifiers of "quality," which make little sense here.

${ }^{18}$ Quoted in Levinson, “Adaptation, Metafiction,” 176.

${ }^{19}$ Landy, "Still Life," 500.

${ }^{20}$ The original music video in particular prefigures glam rock; Jonze is also an adept music video director and enthusiast.

${ }^{21}$ Hilderbrand, “Reviews: 'Adaptation',” passim. 
${ }^{22}$ Donald also raises the song a number of times in relation to its "belonging" in a narrative, suggesting that its own blend of influences make it a difficult fit for any other film that works in a singular dramatic mode.

${ }^{23}$ Hilderbrand, "Reviews: 'Adaptation'," 41, 42.

${ }^{24}$ Robert McKee, Story: Substance, Structure, Style and the Principles of Screenwriting (New York: Regan Books, 1997).

${ }^{25}$ As Jason Mittell puts it, “by highlighting the conventionality of Donald's writing and McKee's guidance, Adaptation reminds us to pay attention to its own unconventional techniques." Jason Mittell, Narrative Theory and Adaptation (New York: Bloomsbury, 2017), 96.

${ }^{26}$ C.f. Andrew Sarris, "Towards a Theory of Film History," in Movies and Methods: An Anthology, Volume 1, ed. Bill Nichols (Berkeley: University of California Press, 1976), 246.

${ }^{27}$ As one might expect in a Jonze film, confusions between the represented and the real recur throughout the narrative, such as the scene in which Donald first outlines his multiple personality serial killer script treatment and Charlie is unable to explain to Donald the difference between diegetic consistency and representational devices or "trick photography."

${ }^{28}$ Here Charlie bundles all the conventions of genre entertainment together into a mundane whole, presenting them as a static entity. Thus car chases come to be an equivalent fantasy to "learning life lessons," and both in need of unequivocal rejection.

${ }^{29}$ Susan Orlean, The Orchid Thief (London: Vintage, 2000), 65-66.

${ }^{30}$ Marks, “Adaptation,” 20. 
${ }^{31}$ Levinson, “Adaptation, Metafiction," 172. The film's final "quote” from The 3 and dedication to Donald in the end credits both point to the film's collapsing of distinctions between various people and the stories that attach to them - we are all made of the same stuff - just as the storytelling process itself becomes indistinguishable from Adaptation's story or plot. See Mittell, Narrative Theory, 117118. The 3 is also representative of the Jonze/Kaufman appetite for embedding little metaphysical jokes in their work together; there are many groups of three to be found in Adaptation whose distinctions have been collapsed.

${ }^{32}$ Marks, “Adaptation,” 28.

${ }^{33}$ Mittell, Narrative Theory, 90.

${ }^{34}$ Marks, "Adaptation," 22. This chimes with the assumptions of terror management theory. For a meta-analysis, see Brian L. Burke, Andy Martens and Erik H. Faucher, “Two Decades of Terror Management Theory: A Meta-Analysis of Mortality Salience Research,” Personality and Social Psychology Review 14, no. 2 (2010): 155-195. ${ }^{35}$ Landy, "Still Life," 506.

${ }^{36}$ Charlie performs this same anthropomorphic work when he transplants women's faces over the orchids and instead of talking to the orchids' specificity, reveals that he is actually thinking sexually about the women he observes through the orchids.

${ }^{37}$ Jablonka and Lamb, Evolution, 199-203.

${ }^{38}$ Stephanie Zacharek, ““Adaptation' and the Perils of Adaptation,” Salon, December 16, 2002, https://www.salon.com/2002/12/16/adaptation_3

${ }^{39}$ Ruzzo, “(In)fidelity,” 304.

${ }^{40}$ Ibid. 305. These narrative elements still become secondary to Orlean's fastidious documentation of the history of Floridian botanical crimes. 
${ }^{41}$ See Rob van Ginkel, “The Makah Whale Hunt and Leviathans Death: Reinventing Tradition and Disputing Authenticity in the Age of Modernity," Etnofoor 17, no. 1/2 (2004): 59; and Benjamin R. Smith and Frances Morphy, eds., The Social Effects of Native Title: Recognition, Translation, Coexistence (Canberra: ANU E Press, 2007), passim.

${ }^{42}$ Levinson, "Adaptation, Metafiction,” 172.

43 Ted Conover, "Flower Power," New York Times Book Review, January 3, 1999, 10.

${ }^{44}$ Orlean, The Orchid Thief, 344.

${ }^{45}$ Robert S. Boynton, The New New Journalism: Conversations with America's best nonfiction writers on their craft (New York: Vintage Books, 2005), 271-292.

${ }^{46}$ Stephen Jay Gould, Life's Grandeur: The Spread of Excellence from Plato to Darwin (London, Vintage: 1997), 140; Marks, “Adaptation,” 39.

${ }^{47}$ Landy, "Still Life," 509.

${ }^{48}$ Ibid. 514.

${ }^{49}$ Roger Ebert, review of Adaptation, by Spike Jonze et al. Rogerebert.com, December 20, 2002, http://www.rogerebert.com/reviews/adaptation-2002

${ }^{50}$ Edward O. Wilson, Consilience: The Unity of Knowledge (New York: Vintage Books, 1999), 139.

${ }^{51}$ Orlean, The Orchid Thief, 41. This passage actually refers to Laroche's life rather than life in general. The book ends with weary disappointment: the scene in which Orlean and Laroche are lost in the swamp. Like the film, the book charts disappointments, which is one of the themes Kaufman has adapted from The Orchid Thief into his own life. 